\title{
Laser Controllable Growth of Graphene via Ni-Cu Alloy Composition Modulation
}

\author{
Xiaohui Ye ${ }^{1} \cdot$ Zhe Lin $^{1} \cdot$ Hongjun Zhang ${ }^{1}$. \\ Hongwei Zhu ${ }^{1} \cdot$ Minlin Zhong ${ }^{1}$
}

\begin{abstract}
Graphene has many unique properties, most of them strongly depend on the number of layers. It is significant to develop a facile approach to realize the controllable growth of graphene with specific number of layers. We ever reported an efficient approach to grow graphene rapidly and locally by laser irradiation. In this work, we offers yet another important feature, to control the number of layers of graphene. $\mathrm{Ni}-\mathrm{Cu}$ alloy has been reported to be used successfully as the catalyst for graphene growth with controllable number of layers. In that case, the Ni-Cu alloys with different compositions were normally formed by thermal evaporation. Here we provide an efficient way to fabricate the Ni-Cu alloy catalysts by laser cladding. Then the high power laser was employed to melt the $\mathrm{Ni}$ and $\mathrm{Cu}$ mixed powders. Different $\mathrm{Ni}-\mathrm{Cu}$ alloy catalysts were formed in a high rate of $720 \mathrm{~mm}^{2} / \mathrm{min}$ with a thickness of $1.2 \mathrm{~mm}$. Then the graphene with controllable layers was rapidly and locally grown on the $\mathrm{Ni}-\mathrm{Cu}$ catalysts by laser irradiation at a high rate $\left(18 \mathrm{~cm}^{2} / \mathrm{min}\right)$ at room temperature. We found that the $\mathrm{Ni}-\mathrm{Cu}$ catalyst with $15 \% \mathrm{Cu}$ could be helpful to grow single layer graphene, which occupied $92.4 \%$ of the entire film. Higher $\mathrm{Cu}$ content didn't promote the growth due to the oxygen involved during the growth process. The controllable growth mechanism of graphene by laser processing was discussed. Combining the rapid catalyst fabrication and graphene synthesis make it a cost- and time-efficient method to produce the controllable graphene films.
\end{abstract}

Keywords Graphene - Laser rapid synthesis · Controllable layer · Ni-Cu alloy · Laser cladding

Minlin Zhong

zhml@tsinghua.edu.cn

1 School of Materials Science and Engineering, Tsinghua University, Beijing 100084, China 


\section{Introduction}

Graphene a single layer or few layers of carbon atoms tightly packed into a two-dimensional (2D) honeycomb lattice, is a basic building block of all graphitic forms $[1,2]$. Currently, graphene is a rapidly rising star, owing to its exceptional properties, e.g., ultra-high electrical conductivity, excellent thermal stability, and extraordinary mechanical properties. The outstanding properties of graphene make it a unique material for many potential applications [3-5], including next generation ultra-compact computers, flat screen displays, sensors, solar cells, conducting plastics or ceramics, micro-electro-mechanical devices and novel protection coatings [6-9].

The distinct properties of graphene strongly depend on its layers. Raman spectra for single layer, bilayer, and multilayer are different [10-12], reflecting the changes in their electron bands. The optical transparency of monolayer graphene can reach up to $97.7 \%$. The opacity increases with membranes' thickness, and each graphene layer adds $2.3 \%$ [13]. The electrical properties and structures of single layer, bilayer, and multilayer graphene show huge differences. The electrical resistance decrease as the number of layers increases [14]. Owing to the specific properties, the graphene with different layers can be applied to various fields. The single-layer graphene has a zero band gap, and its conduction and valence bands are shaped like an inverted pair of cones that meet in a single point at $E=0$ in momentum space [15]. Due to the special structure, the carrier mobility of single-layer graphene is extremely high $(2 \times$ $10^{5} \mathrm{~cm}^{2} / \mathrm{vs}$ ) [5,7]. The actual single-layer graphene is synthesized through exfoliation of highly oriented pyrolytic graphite (HOPG), which is for fundamental research due to the small size of graphene obtained. As for bilayer graphene, it has a continuously tunable band gap under electric field and shows unique quantum-mechanical behavior. It makes that bilayer graphene has great potential application for optoelectronics and microprocessors [15-18]. Once the number of layers exceeds ten, graphene film would share a band structure similar to graphite $[15,19]$. To realize the specific properties, it is significant to develop a controllable approach to grow the graphene with specific number of layers for practical applications.

One of the most important parameters of graphene growth is specific catalyst. For now, the following metals have been used as growth catalysts, i.e., Ru, Ir, $\mathrm{Co}, \mathrm{Re}, \mathrm{Ni}, \mathrm{Cu}, \mathrm{Pt}, \mathrm{Pd}$ [20-24]. Among them, $\mathrm{Ni}$ and $\mathrm{Cu}$ are the most widely-used metals. For $\mathrm{Ni}$, the carbon sources are dissolved into the metal at high temperature. With the temperature cooling down, the solubility of $\mathrm{C}$ in $\mathrm{Ni}$ decreases and the extra carbon sources then precipitate out on the Ni surface to form graphene. During this processing, the precipitation of carbon sources cannot be controlled, so that the thickness of graphene is uncontrollable [24]. While, due to the indissolubility of $\mathrm{C}$ in $\mathrm{Cu}$, it is very easy to grow singlelayer graphene on $\mathrm{Cu}$. The carbon sources are mainly absorbed by $\mathrm{Cu}$ atoms at high temperature, and then the single-layer graphene is formed on the surface [24]. Combining these two growth mechanisms, we can realize the controllable growth of graphene. Several approaches for synthesizing controllable graphene have been developed. Liu, et al. [20] reported a new technique to synthesis 
graphene, called universal segregation growth. They obtained graphene wafers from $\mathrm{Ni}, \mathrm{Co}, \mathrm{Fe}, \mathrm{Cu}$ and $\mathrm{Cu}-\mathrm{Ni}$ alloy films via thermal annealing by introducing carbon sources. They demonstrated that monolayer and bilayer graphene films were grown on $\mathrm{Cu}-\mathrm{Ni}$ alloy by combining the distinct segregation behaviors of $\mathrm{Cu}$ and $\mathrm{Ni}$. Then they studied the relationship of graphene layer and the content of $\mathrm{Ni}$ and $\mathrm{Cu}$ in the alloy [15]. They found that increasing the atomic percentage of $\mathrm{Cu}$ in $\mathrm{Ni}-\mathrm{Cu}$ alloy tended to segregate thinner uniform graphene. Dai, et al. [21] used a Ni-Mo alloy to suppress the carbon precipitation and activates a self-limited growth for homogeneous monolayer graphene. A similar work by Weatherup et al. [22] reported that Au-Ni alloy was prepared for the large single crystal growth. Besides altering the composition of the catalysts, Chen et al. [14] controlled the graphene thickness by varying the deposition temperature and cooling rate, but also on $\mathrm{Ni}-\mathrm{Cu}$ alloy foils. A high cooling rate and less deposition time would be helpful to grow single layer graphene. Laser cladding is a hard facing process that uses a high-powered laser beam to melt the coating material and a thin layer of the substrate to form a pore- and crackfree coating [25-27]. It is a convenient way to fabricate the alloy coating. Varying the proportion of original materials, the different alloy coatings would be obtained.

With these approaches, it is feasible to control the thickness of graphene by modulating the composition of the binary alloy as the catalytic catalyst. However, almost all of the catalyst was fabricated by thermal evaporation, which is a time- consuming approach with the limited thickness of catalyst. Meanwhile, the synthesis of graphene was always involved a high temperature process for a long time to segregate carbon atoms. We ever reported an efficient approach to grow graphene rapidly and locally by laser irradiation [23]. This laser approach combines lots of merits, i.e., large-area growth, patterned graphene and fast growth for practical applications. In that reported work, graphene was synthesized by laser irradiation on solid carbon source coated on nickel surface in ambient condition. The rapid solidification made it possible to grow graphene at a high rate compared to conventional approaches. Arbitrary patterns designed by computer aided design (CAD) software were fabricated directly on $\mathrm{Ni}$ substrates without additional mask or setup. Together the rapid heating and cooling made a cost- and time-efficient and eco-friendly method to produce high-quality graphene films [23].

Integrated with above work, we further introduce here the graphene layer control by modulating the composition of the catalyst substrate. We used a high power density continuous wave $(\mathrm{CW})$ fiber laser to deposit a composition-designable $\mathrm{Ni}-\mathrm{Cu}$ alloy onto a substrate. The Ni-Cu alloy was deposited in a high rate up to $720 \mathrm{~mm} / \mathrm{min}$ with a changeable thickness up to $1.2 \mathrm{~mm}$. Then the laser was further applied to growth the graphene as reported earlier. The high power laser radiated the $\mathrm{Ni}-\mathrm{Cu}$ surface together with the as-coated carbon with a very high heating rate up to a temperature of $\sim 1600{ }^{\circ} \mathrm{C}$, formed a large-area bath and then cooled down at a very high cooling rate. The rapid solidification made it possible to grow graphene at a high rate $\left(18 \mathrm{~cm}^{2} / \mathrm{min}\right)$. In addition to the merits of graphene growth by laser, e.g., large-area growth, patterned growth and mass production, in this work, we offers yet another important feature, to control the number of layers of graphene. 


\section{Material and Methods}

\section{Ni-Cu Alloy with Specific Composition}

In this study, we first focus on the influence of catalyzers on graphene growth. Based on the mechanism of precipitation growth, it is feasible to control graphene layers by varying the proportion of $\mathrm{Cu}$ and $\mathrm{Ni}$ in catalyst [15,20-22]. Figure 1a shows the schematic of $\mathrm{Ni}-\mathrm{Cu}$ catalyst fabrication by laser cladding. High power density continuous wave fiber laser was employed to fabricate the catalyst. High pure (99.99\%) Cu and Ni powders of uniform size, about $75 \mu \mathrm{m}$ in varying proportions (listed in Table 1) were assembled into a side shaft powder feeding apparatus (BAMTRI, DPSF-2). With the assistance of airflow, the pre-mixed powders were delivered into the irradiated area by laser beam. The substrate can be any commonly used metals. Almost at the same time, the mixed powders and the substrate were heated and melted caused by laser irradiation. The molten powders then dropped down into the bath just forming in the substrate surface. Once the laser moved forward, the Ni-Cu alloy coating was formed on the substrate surface. The quality of $\mathrm{Ni}-\mathrm{Cu}$ catalyst strongly depended on laser power density, scanning rate and powder feeding rate. Table 1 lists the optimal conditions for different catalysts, and the number in the first column represents the content of $\mathrm{Cu}$.

\section{Controllable Graphene Synthesis by Laser Irradiation}

The catalysts were prepared and then polished to a smooth and flat surface. The graphite powders with uniform size of $\Phi 50 \mathrm{~nm}$ were used as the carbon source. These nano-powders were mixed with alcohol (analytical reagent) to form a suspension. The mixed ratio was $1.0 \mathrm{~g}$ powders with $1.6 \mathrm{ml}$ alcohol. Then, the spin coater (SC-1B) was applied to prepare the carbon coatings with the thickness of $\sim 20 \mu \mathrm{m}$. The fiber laser were employed to scan the pre-coated carbon source on the $\mathrm{Ni}-\mathrm{Cu}$ catalysts, as shown in Fig. 1b. In this approach, the Ni-Cu surface together with the as-coated carbon is heated at a high rate up to $\sim 2000{ }^{\circ} \mathrm{C}$, forming a bath and then cools down at rate up to

a

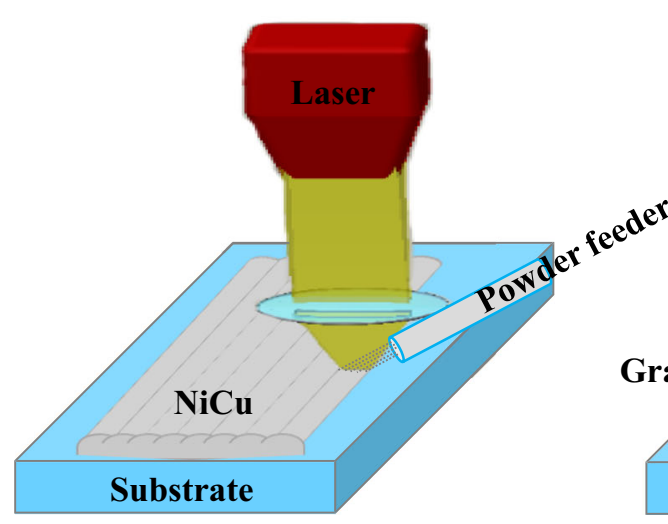

b

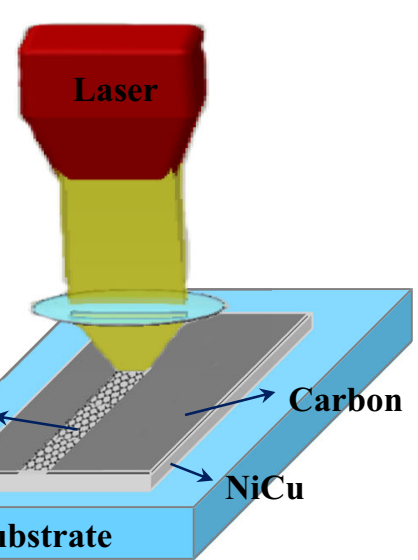

Fig. 1 Schematic of a Ni-Cu catalyst fabrication by laser cladding. b Layer controllable graphene synthesis 
Table 1 The optimal conditions for different catalysts

\begin{tabular}{llllll}
\hline Sample & $\begin{array}{l}\text { Composition } \\
(\text { wt. \%) }\end{array}$ & Power density $\left(\mathrm{W} / \mathrm{cm}^{2}\right)$ & Scanning rate $(\mathrm{mm} / \mathrm{s})$ & Powder feeding rate $(\mathrm{g} / \mathrm{min})$ \\
\cline { 2 - 3 } & $\mathrm{Cu}$ & $\mathrm{Ni}$ & & \\
\hline $\mathrm{Cu} 0$ & 0 & 100 & $2.15 \times 10^{4}$ & 4 & 13.33 \\
$\mathrm{Cu} 5$ & 5 & 95 & $2.15 \times 10^{4}$ & 4 & 13.33 \\
$\mathrm{Cu} 15$ & 15 & 85 & $2.15 \times 10^{4}$ & 4 & 13.33 \\
$\mathrm{Cu} 25$ & 25 & 75 & $2.12 \times 10^{4}$ & 4 & 13.33 \\
$\mathrm{Cu} 35$ & 35 & 65 & $2.00 \times 10^{4}$ & 4 & 13.33 \\
$\mathrm{Cu} 50$ & 50 & 50 & $1.85 \times 10^{4}$ & 4 & 13.33 \\
$\mathrm{Cu} 75$ & 75 & 25 & $1.58 \times 10^{4}$ & 4 & \\
\hline
\end{tabular}

$10^{3} \sim 10^{4}{ }^{\circ} \mathrm{C} / \mathrm{s}$. When the laser was shut off, graphene could be available immediately. The formation of graphene was implemented by fiber laser with a Gauss beam of $\Phi 3$ $\mathrm{mm}$. The laser power density was $14.1 \times 10^{3} \mathrm{~W} / \mathrm{cm}^{2}$, and the scanning rate was $60 \mathrm{~cm} /$ min with $25 \mathrm{~L} / \mathrm{min}$ argon $(99.99 \%$ ) as shielding gas.

\section{Characterization}

The component distributions of the $\mathrm{Ni}-\mathrm{Cu}$ catalysts were detected by energy dispersive X-ray spectroscopy (EDS). The structures of catalysts were characterized by X-ray diffraction (XRD, Bruker, D8 Advance), from 20 to $100^{\circ}$ with scanning rate of $8^{\circ} \mathrm{min}$. As-grown graphene were characterized by optical microscopy, scanning electron microscopy (SEM, LEO-1530), Raman spectroscopy (Renishaw 2000), Raman imaging spectroscopy (Nanophoton, Raman-11), and auger electron spectroscopy (AES, ULVAC-PHI, PHI-700). The topography of graphene was observed by optical and SEM images. The layer number of graphene was identified by Raman spectra and AES.

\section{Results and Discussion}

\section{Composition of Ni-Cu Alloy Modulated by Laser Cladding}

$\mathrm{Ni}-\mathrm{Cu}$ catalysts were prepared by laser cladding successfully. Figure $2 \mathrm{a}$ shows the macrograph of $\mathrm{Ni}-\mathrm{Cu}$ alloy after laser cladding. The good formation of $\mathrm{Ni}-\mathrm{Cu}$ alloy without pores or cracks was obtained under the optimal condition. The component distributions were analyzed by EDS, as shown in Figs. 2b and $\mathrm{g}$ and Table 2. The red images present $\mathrm{Cu}$ distributions and the green ones are Ni distributions. The color images show that there are uniform distributions of $\mathrm{Cu}$ and $\mathrm{Ni}$ in each sample. The actual compositions are listed in Table 2. It can be observed the loss of $\mathrm{Cu}$ and introduction of oxygen, due to high temperature and open condition during laser cladding. However, the small loss of $\mathrm{Cu}$ could be acceptable. The EDS results show that the catalysts prepared by laser cladding are homogenous. 


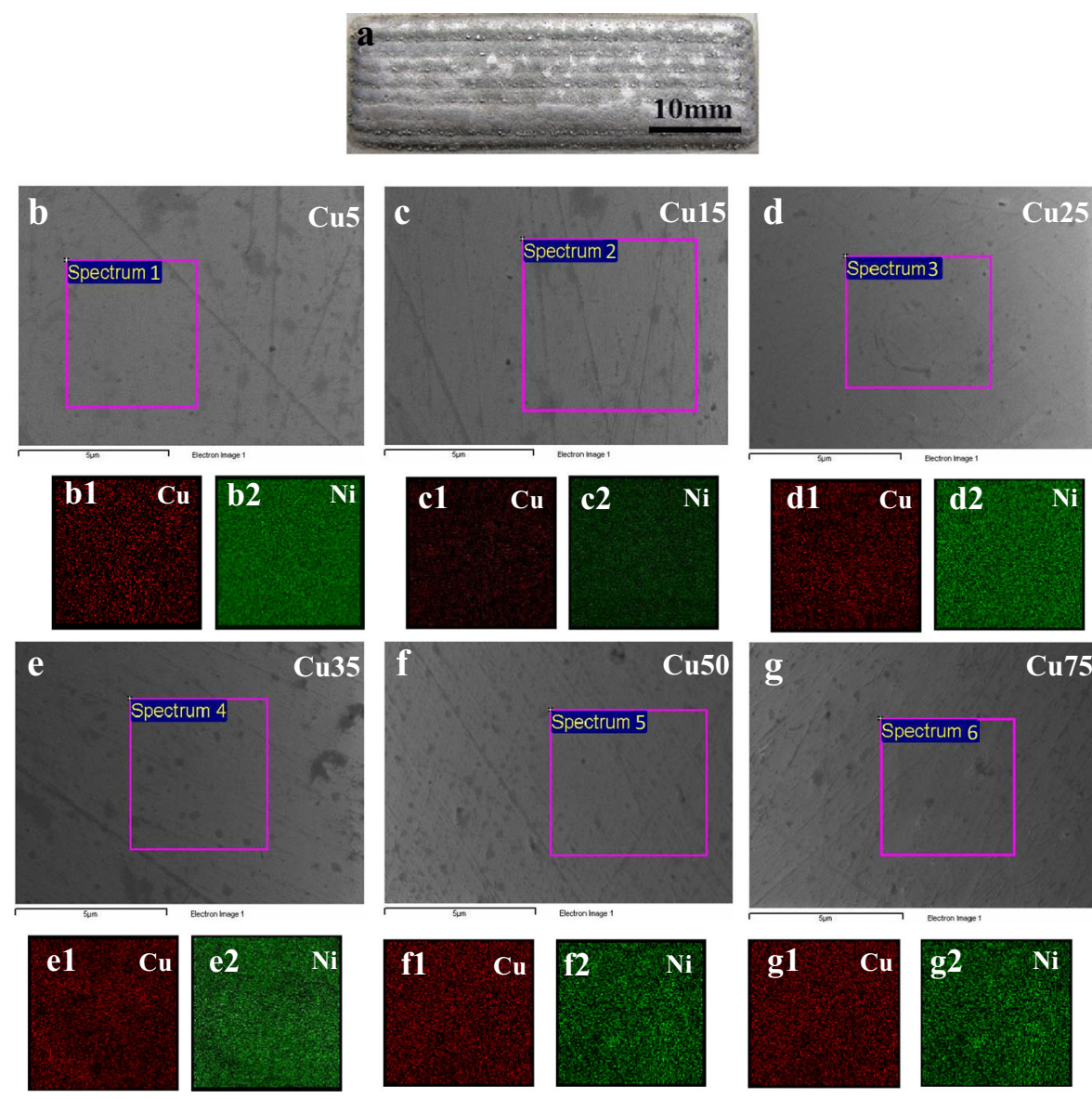

Fig. 2 a Macrograph of Ni-Cu alloy. b-g Cu and Ni distributions of different catalysts. The red images present $\mathrm{Cu}$ distributions and the green ones show Ni distributions

XRD was used for catalyst structure analysis. Figure 3 a shows the spectra of different catalysts with $\mathrm{Cu}$ increasing from bottom to up. Four characteristic peaks can be observed, calibrated as (111), (200), (220) and (311) of face-centered cubic $(f c c)$.

Table 2 The actual composition in each catalyst

\begin{tabular}{llll}
\hline Sample & \multicolumn{2}{l}{ Actual composition } & \\
\cline { 2 - 3 } & $\mathrm{Cu}($ wt. \%) & Ni (wt. \%) & O (wt. \%) \\
\hline $\mathrm{Cu} 5$ & 3.3 & 96.7 & 0 \\
$\mathrm{Cu} 15$ & 13.01 & 86.42 & 0.57 \\
$\mathrm{Cu} 25$ & 22.83 & 76.4 & 0.77 \\
$\mathrm{Cu} 35$ & 31.94 & 67.26 & 0.8 \\
$\mathrm{Cu} 50$ & 39.1 & 59.85 & 1.05 \\
$\mathrm{Cu} 75$ & 73.91 & 22.73 & 3.36 \\
\hline
\end{tabular}



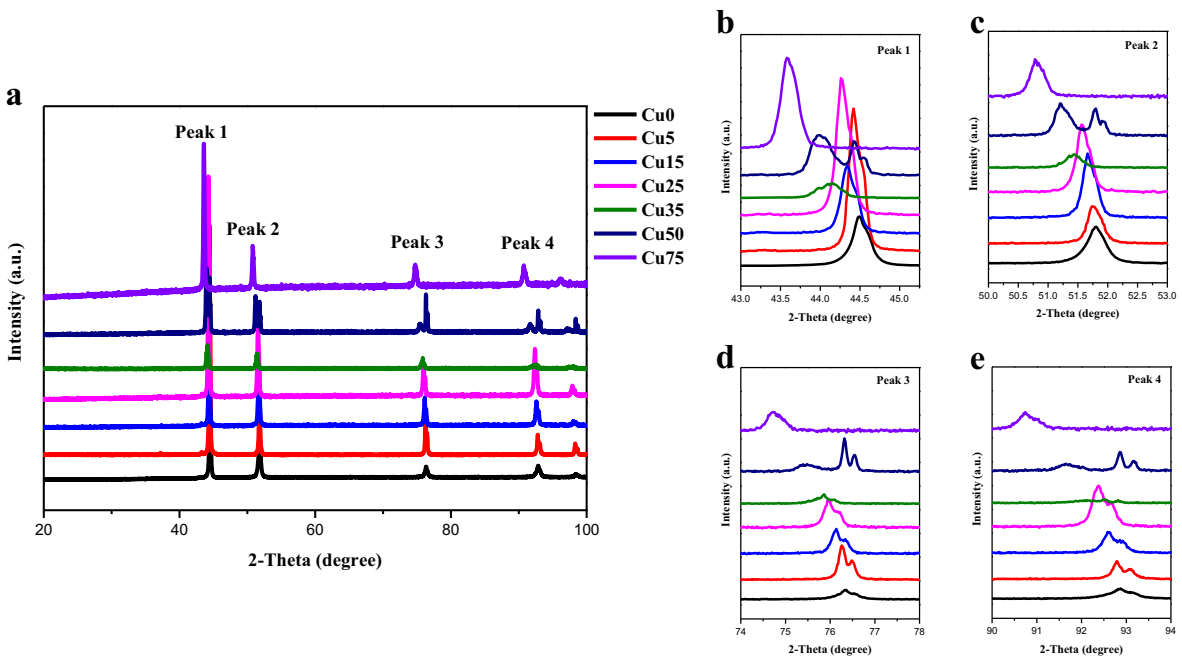

Fig. 3 a XRD spectra of different catalysts. b, c, $\mathbf{d}$ and e represent different peaks in a, respectively

The similar spectra demonstrate that the structures of all the samples are the same, i.e., $f c c$, meaning that the structure of $\mathrm{Ni}-\mathrm{Cu}$ alloy is close to that of pure $\mathrm{Ni}$ (the bottom spectrum). However, it is also different from each other. Figures $3 \mathrm{~b}$ and e display the four characteristic peaks respectively, and all these peaks shift left as $\mathrm{Cu}$ increasing. The left shift implies the increasing of interplanar spacing. For $f c c$, the larger interplanar spacing equals to a bigger structure cell. The reason for the left shift is that pure $\mathrm{Cu}$ has a bigger structure cell (lattice constant $\mathrm{a}_{\mathrm{Cu}}=3.6149 \AA$ ) than pure Ni (lattice constant $\mathrm{a}_{\mathrm{Ni}}=3.5238 \AA$ ). Consequently, the structure is closer to that of pure $\mathrm{Cu}$ as the $\mathrm{Cu}$ content increases.

\section{Controllable Graphene Growth by Laser Irradiation}

The graphene fabrication was implemented by fiber laser direct irradiation on the prepared $\mathrm{Ni}-\mathrm{Cu}$ alloy catalysts. With the radiation, the $\mathrm{Ni}-\mathrm{Cu}$ surface together with the as-coated carbon is heated at a rate of up to $10^{4}{ }^{\circ} \mathrm{C} / \mathrm{s}$ to a temperature of around $2000^{\circ} \mathrm{C}$, forming a large-area bath and then cools down at rate of up to $10^{3} \sim 10^{4}{ }^{\circ} \mathrm{C} / \mathrm{s}$. The topography of graphene was characterized by optical microscopy and SEM, as seen in Fig. 4. There are amount of tiny strips on the pure Ni surface (Cu0) (Fig. 4a). The magnified SEM image shows the obvious wrinkles of graphene (Fig. 4h). Once Cu added, the strips are much less than that of pure Ni, as seen in Fig. 4b, c, i and j. When the content of $\mathrm{Cu}$ came to $25 \%$ and $35 \%$, graphene films turned to discontinuous, as shown in Fig. 4d, e, $\mathrm{k}$ and $\mathrm{l}$. For $\mathrm{Cu} 50$ and $\mathrm{Cu} 75$, the wrinkles of graphene cannot be observed any more (Fig. 4f, g, $\mathrm{m}$ and $\mathrm{n}$ ). It is hard to tell whether it is graphene or not by these topographies, due to the loss of graphene typical topography. The information of topography demonstrate that appropriate ratio of $\mathrm{Cu} / \mathrm{Ni}$, i.e., $\mathrm{Cu}$ of $5 \%$ and $15 \%$, can be helpful for formation continuous graphene films, rather than higher content of $\mathrm{Cu}(25 \%$ and over).

Raman spectroscopy is an efficient way to characterize carbon materials. Ferrari et al. [10] pointed out that $\mathrm{G}$ band $\left(\sim 1580 \mathrm{~cm}^{-1}\right)$ reflects the doubly degenerate zone 

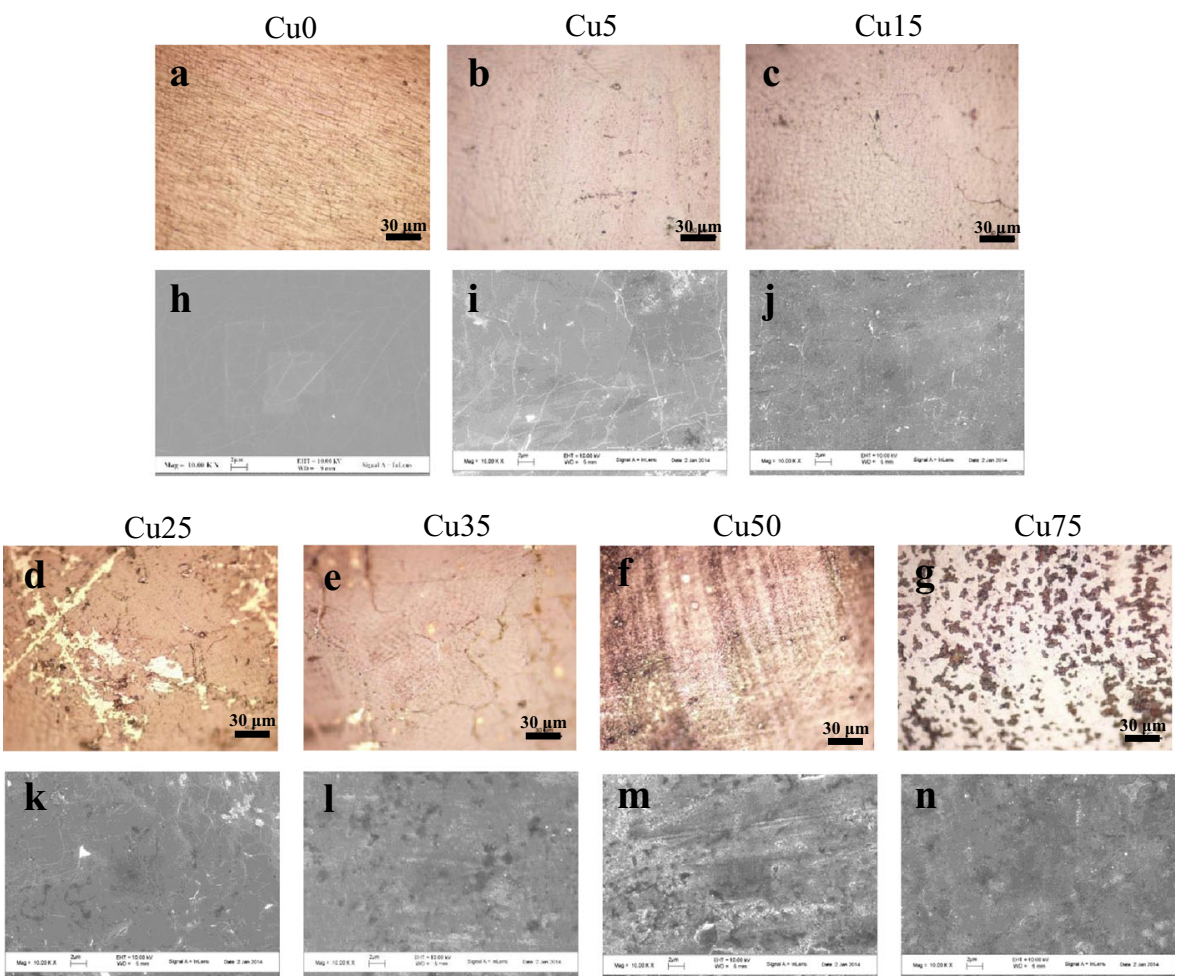

Fig. 4 Topography of graphene on different catalysts. a-g optical images. Share the same scale bar of $30 \mu \mathrm{m}$. h-n SEM images. Scale bars: $5 \mu \mathrm{m}$

center $\mathrm{E}_{2 \mathrm{~g}}$ mode while $\mathrm{D}$ band $\left(\sim 1350 \mathrm{~cm}^{-1}\right)$ indicates the absence of a significant number of defects. The $2 \mathrm{D}$ band $\left(\sim 2700 \mathrm{~cm}^{-1}\right)$ provides information about the number of layers. The increase in layers leads to a significant decrease of the relative intensity of 2D $\left(I_{2 D}\right)$ with a blue shift. Here, we performed Raman imaging and Raman spectra to figure out the relationship between catalysts and graphene layers. Figures $5 \mathrm{a}$ and $\mathrm{g}$ display the $I_{2 D} / I_{G}$ mapping results in an area of $254 \times 25 \mu^{2}$. The lighter color represents a higher value of $I_{2 \mathrm{D}} / I_{\mathrm{G}}$ and the dark blue represents a lower one. Raman spectra were extracted from the Raman imaging accordingly, as shown in Figs. 5h and n. The ratio of $I_{2 \mathrm{D}} / I_{\mathrm{G}}$ greater than 1.0 was calculated from the Raman mapping software, which means that $2 \mathrm{D}$ peak intensity is greater than $\mathrm{G}$ peak. This is the typical trait of monolayer or bilayer (1-2 L) graphene. So the ratio of $I_{2 \mathrm{D}} / I_{\mathrm{G}}$ greater than 1.0 equals to the ratio of 1-2 layer graphene (Fig. 5o). Based on the relationship between the relative intensity of $2 \mathrm{D}\left(I_{2 D}\right)$ and graphene layers, a higher $I_{2 \mathrm{D}} / I_{\mathrm{G}}$ implies a lower number of graphene layers. For the pure Ni catalyst $(\mathrm{Cu} 0)$, most of the detection area was covered by multilayer graphene films, and the occupancy of 1-2 L graphene is $58.8 \%$. With $5 \% \mathrm{Cu}$ adding into the catalyst, $1-2 \mathrm{~L}$ graphene occupied up to $78.7 \%$ of all the detection area. $15 \% \mathrm{Cu}$ of Ni-Cu alloy brought a high Ratio of 1-2 L graphene, up to $92.4 \%$. Meanwhile, the higher $\mathrm{Cu}$ content, e.g., $25 \%$ and $35 \%$, could not keep a higher occupancy of 1-2 L graphene, and the 1-2 L graphene ratios are $70.2 \%$ and $64.3 \%$. When $\mathrm{Cu}$ content is over $50 \%$, there is no typical trait of graphene from the 

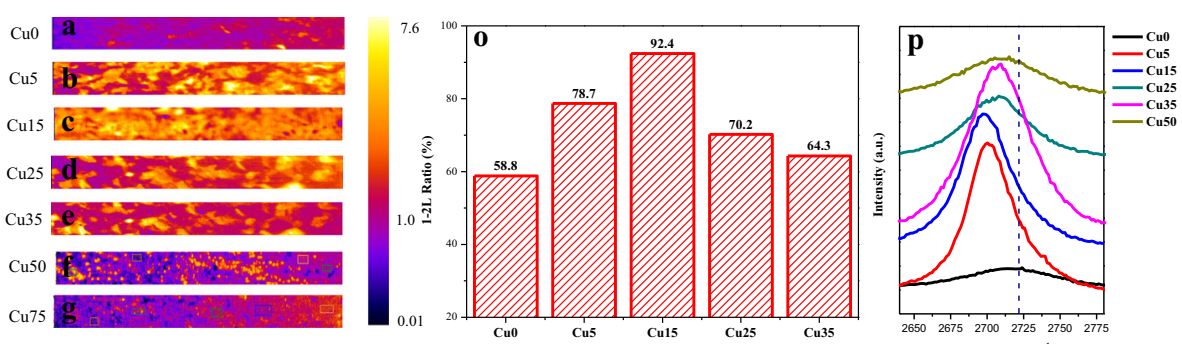

$I_{2 D} / I$ Raman shift $\left(\mathrm{cm}^{-1}\right)$
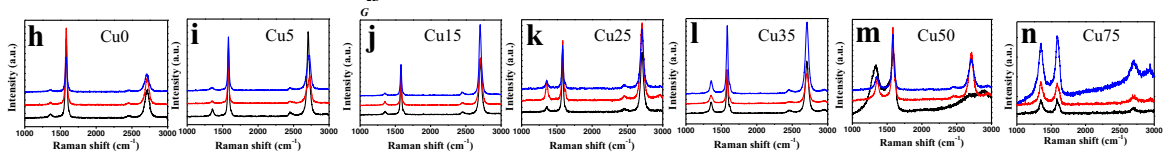

Fig. 5 a-g $532 \mathrm{~nm}$ Raman imaging of $I_{2 D} / I_{G}$. h-n Raman spectra extracted from the Raman imaging accordingly. o The ratio of 1-2 layer graphene occupied in different samples. (p) 2D peak position shift of different samples

Raman spectra. Figure $5 \mathrm{p}$ shows the position shift of 2D peak. Compared to $\mathrm{Cu} 0$, there was $24 \mathrm{~cm}^{-1}$ red shift of $\mathrm{Cu} 5$ and $29 \mathrm{~cm}^{-1}$ red shift of $\mathrm{Cu} 15 . \mathrm{Cu} 25$ and $\mathrm{Cu} 35 \mathrm{had}$ slight red shift, $8 \mathrm{~cm}^{-1}$ and $9 \mathrm{~cm}^{-1}$, respectively. The red shift of $2 \mathrm{D}$ peak demonstrated the decrease of graphene layers.

AES depth profile analysis was employed to study the element distributions from surface to a depth of $6 \mathrm{~nm}$, by using a sputtering rate $2 \mathrm{~nm} / \mathrm{min}$. The depth profile of element $\mathrm{C}$ can be used to identify the number of graphene layer. Every layer of graphene is $0.34 \mathrm{~nm}$. Figure 6 provides the depth profiles of $\mathrm{C}, \mathrm{O}, \mathrm{Ni}$ and $\mathrm{Cu}$ in different catalysts. Here, we considered the depth where $\mathrm{C}$ dropped down and Ni rose up as the thickness of graphene. It can be seen (Fig. 6a) that for pure $\mathrm{Ni}, \mathrm{C}$ remains a high proportion $(>60 \%)$ in the whole depth of $6 \mathrm{~nm}$, and there is no cross point with the Ni distribution line, meaning that the thickness of graphene is more than $6 \mathrm{~nm}$. In this case, the graphene would be multilayer films. Figures $6 \mathrm{~b}, \mathrm{c}$ and $\mathrm{d}$ show the significant drop of $\mathrm{C}$ and obvious rise of $\mathrm{Ni}$ at $0.75,0.5$, and $0.98 \mathrm{~nm}$, respectively. Accordingly, the layers of graphene would be $2 \mathrm{~L}, 1 \mathrm{~L}$ and $3 \mathrm{~L}$. These results demonstrate that the catalyst with $15 \% \mathrm{Cu}$ is the most appropriate substrate to grow single-layer graphene; the bilayer graphene tend to be grown on the catalyst with $5 \%$ $\mathrm{Cu}$; the catalyst with $25 \% \mathrm{Cu}$ is available for tri-layer graphene. Figure 6e also shows a higher of $\mathrm{C}$ content than $\mathrm{Ni}$ and $\mathrm{Cu}$ in the whole profile. The controllable growth by $\mathrm{Cu}$ addition doesn't work anymore, when $\mathrm{Cu}$ is over $35 \%$.

\section{Mechanism of Controllable Graphene Growth by Laser Irradiation}

From the above results, the $\mathrm{Ni}-\mathrm{Cu}$ catalysts can effectively control the growth of graphene. The appropriate $\mathrm{Cu}$ content $(5 \%$ and $15 \%)$ is helpful to form continuous and large-area 1-2 L graphene films. Once the content of $\mathrm{Cu}$ reached $25 \%$ and $35 \%$, the graphene turned to heterogeneous and multilayer. A higher $\mathrm{Cu}$ content, like $50 \%$ and $75 \%$, could not grow graphene successfully. These results are so different from the other reports. Usually, the higher $\mathrm{Cu}$ content leads to the higher coverage of 1-2 L graphene $[15,20]$, and the pure $\mathrm{Cu}$ can easily grow the single layer graphene. However, in this work, the higher $\mathrm{Cu}$ is invalid to control the graphene growth. As studied before 

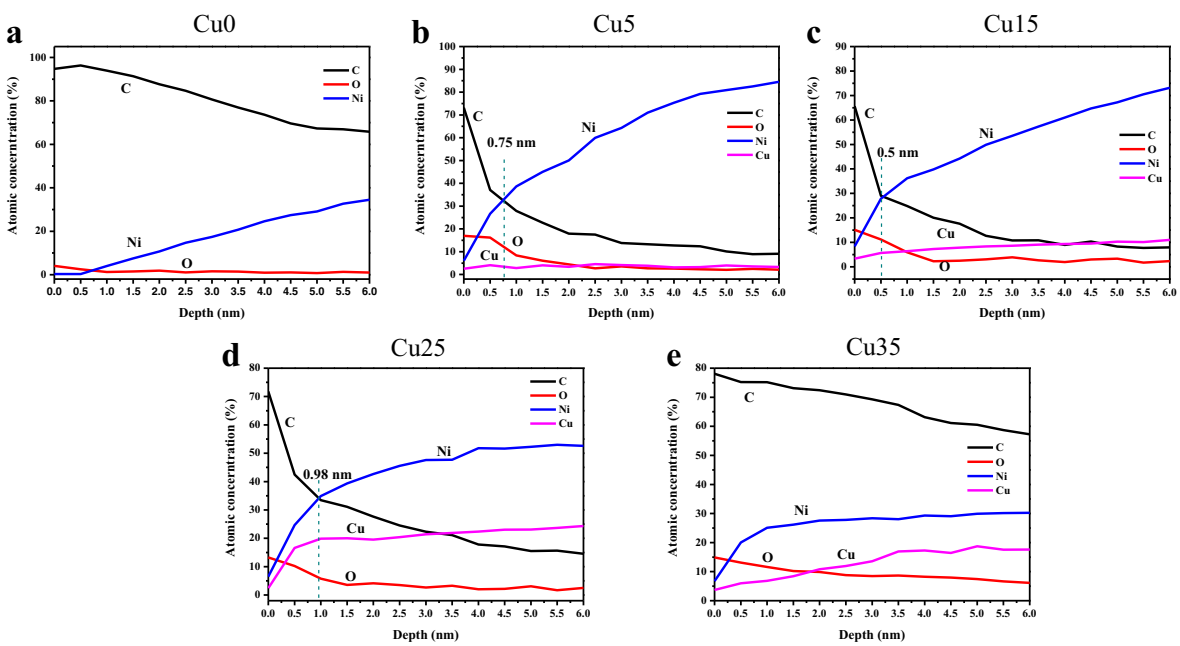

Fig. 6 Depth profiles of $\mathrm{C}, \mathrm{O}, \mathrm{Ni}$ and $\mathrm{Cu}$ by AES analysis. a $\mathrm{Cu} 0$; b $\mathrm{Cu} 5$; c $\mathrm{Cu} 15$; d $\mathrm{Cu} 25$; e $\mathrm{Cu} 35$

[24,28-31], there are two different growth mechanism of graphene on $\mathrm{Ni}$ and $\mathrm{Cu}$. Graphene is grown on $\mathrm{Cu}$ by surface absorbed. It is an easy way to grow the singlelayer graphene. Multilayer graphene is grown on Ni by carbon atoms precipitation from the bulk out to the surface. Figure 7 shows the schematic of mechanism of controllable growth. Here, both of the two kinds of growth mode were involved to realize a controllable growth. In lower $\mathrm{Cu}$ case, the controllable growth was similar with other works $[15,20]$. In the surface layer, carbon atoms preferred to precipitate from $\mathrm{Ni}$, rather than from $\mathrm{Cu}$, when the $\mathrm{Cu}$ atoms occupied some positions to reduce the proportion of $\mathrm{Ni}$ atoms, the precipitation of carbon atoms was also reduced and the few-layer graphene can be formed. For the situation of high $\mathrm{Cu}$ content, the laser processing should take the responsibility for invalid controllable growth. With the radiation of a high power density laser, the catalyst surface together with the ascoated carbon is heated at a rate of up to $10^{4}{ }^{\circ} \mathrm{C} / \mathrm{s}$ to a temperature of around $2000{ }^{\circ} \mathrm{C}$, forming a bath to dissolve carbon source and then cools down to precipitate carbon atoms and form graphene films. All the process was implemented in the open environment. At high temperature, $\mathrm{Cu}$ atoms are likely to combine the oxygen to form $\mathrm{CuO}$. The high content of $\mathrm{O}$ in $\mathrm{Cu} 35$ is shown in Fig. 6e. It is not difficult to infer that there is more oxygen in $\mathrm{Cu} 50$ and $\mathrm{Cu} 75$. Therefore, the positions of original $\mathrm{Cu}$ has changed into the $\mathrm{CuO}$, which cannot contribute to the growth of graphene. So there is no more graphene in the area where $\mathrm{Cu}$ atoms should be but

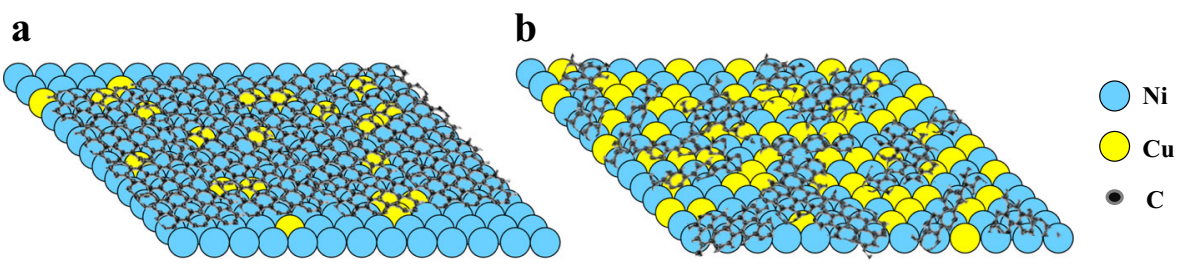

Fig. 7 Mechanism of graphene layer control. a The growth of graphene in the catalyst with lower $\mathrm{Cu}$ content. b The growth of graphene in the catalyst with higher $\mathrm{Cu}$ content 
actually $\mathrm{CuO}$ occupied. It results in the discontinuous graphene growth. When $\mathrm{Cu}$ atoms occupy most of the surface, the graphene growth can be completely restrained, as seen in Figs. 5f, g, $\mathrm{m}$ and $\mathrm{n}$.

\section{Conclusions}

We have succeeded in developing an engineering approach for the controllable graphene growth by laser process at room temperature. A high power fiber laser was used for $\mathrm{Ni}-\mathrm{Cu}$ alloy preparation and controllable graphene growth. Different $\mathrm{Ni}-\mathrm{Cu}$ alloy catalysts were formed in a high rate of $720 \mathrm{~mm}^{2} / \mathrm{min}$ with a thickness of $1.2 \mathrm{~mm}$. EDS analysis showed that the catalysts remained a uniform surface without defects. Then the graphene with controllable layers was rapidly and locally grown on the $\mathrm{Ni}-\mathrm{Cu}$ catalysts by laser irradiation at a high rate $\left(18 \mathrm{~cm}^{2} / \mathrm{min}\right)$. The topographies of the samples displayed that $\mathrm{Cu} 5$ and $\mathrm{Cu} 15$ are the better catalysts than others, owing to the continuous formation and less wrinkles. Raman and AES results showed Cu15 was the most appropriate catalyst to grow the single layer graphene, which occupied $92.4 \%$ of entire film. The catalysts with higher $\mathrm{Cu}$ content would not be workable to control the graphene layers, mainly due to the oxygen involved during the growth process.

Acknowledgments The authors greatly thank the funding support by China National Key Basic Research and Development Program (2011CB013000).

\section{References}

1. Novoselov, K.S., Geim, A.K., Morozov, S.V., Jiang, D., Zhang, Y., Dubonos, S.V., et al.: Electric field effect in atomically thin carbon films. Science 306, 666-669 (2004)

2. Novoselov, K.S., Fal'Ko, V.I., Colombo, L., Gellert, P.R., Schwab, M.G., Kim, K.: A roadmap for graphene. Nature 490, 192-200 (2012)

3. Ferrari, A.C., Basko, D.M.: Raman spectroscopy as a versatile tool for studying the properties of graphene. Nat. Nanotechnol. 8, 235-246 (2013)

4. Zang, J.F., Ryu, S., Pugno, N., Wang, Q.M., Tu, Q., Buehler, M.J., et al.: Multifunctionality and control of the crumpling and unfolding of large-area graphene. Nat. Mater. 12, 321-325 (2013)

5. Neto, A.C., Guinea, F., Peres, N.M.R., Novoselov, K.S., Geim, A.K.: The electronic properties of graphene. Rev. Mod. Phys. 81, 109 (2009)

6. Liu, H., Huang, J., Li, X., Liu, J., Zhang, Y., Du, K.: Flower-like $\mathrm{SnO}_{2}$ /graphene composite for highcapacity lithium storage. Appl. Surf. Sci. 258, 4917-4921 (2012)

7. Kim, K.S., Zhao, Y., Jang, H., Lee, S.Y., Kim, J.M., Kim, K.S., et al.: Large-scale pattern growth of graphene films for stretchable transpatent electrodes. Nature 457, 706-710 (2009)

8. Dean, C.R., Young, A.F., Meric, I., Lee, C., Wang, L., Sorgenfrei, S., et al.: Boron nitride substrates for high-quality graphene electronics. Nat. Nanotechnol. 5, 722-726 (2010)

9. Chen, S.S., Brown, L., Levendorf, M., Cai, W.W., Ju, S.Y., Edgeworth, J., et al.: Oxidation resistance of graphene-coated $\mathrm{Cu}$ and CuNi alloy. ACS Nano 5, 1321-1327 (2011)

10. Ferrari, A.C., Meyer, J.C., Scardaci, V., Casiraghi, C., Lazzeri, M., Mauri, F., et al.: Raman spectrum of graphene and graphene layers. Phys. Rev. Lett. 97, 187401 (2006)

11. Ni, Z., Wang, Y., Yu, T., Shen, Z.: Raman spectroscopy and imaging of graphene. Nano Res. 1, 273-291 (2008)

12. Casiraghi, C., Hartschuh, A., Lidorikis, E., Qian, H., Harutyunyan, H., Gokus, T., et al.: Rayleigh imaging of graphene and graphene layers. Nano Lett. 7, 2711-2717 (2007)

13. Nair, R.R., Blake, P., Grigorenko, A.N., Novoselov, K.S., Booth, T.J., Stauber, T., et al.: Fine structure constant defines visual transparency of graphene. Science 320, 1308 (2008) 
14. Chen, S., Cai, W., Piner, R.D., Suk, J.W., Wu, Y., Ren, Y., et al.: Synthesis and characterization of largearea graphene and graphite films on commercial $\mathrm{Cu}-\mathrm{Ni}$ alloy foils. Nano Lett. 11, 3519-3525 (2011)

15. Liu, X., Fu, L., Liu, N., Gao, T., Zhang, Y., Liao, L., Liu, Z.: Segregation growth of graphene on Cu-Ni alloy for precise layer control. J. Phys. Chem. C 115, 11976-11982 (2011)

16. Zhang, Y., Tang, T.T., Girit, C., Hao, Z., Martin, M.C., Zettl, A., et al.: Direct observation of a widely tunable bandgap in bilayer graphene. Nature 459, 820-823 (2009)

17. Partoens, B., Peeters, F.M.: From graphene to graphite: electronic structure around the K point. Phys. Rev. B 74, 075404 (2006)

18. Ohta, T., Bostwick, A., Seyller, T., Horn, K., Rotenberg, E.: Controlling the electronic structure of bilayer graphene. Science 313, 951-954 (2006)

19. Craciun, M.F., Russo, S., Yamamoto, M., Oostinga, J.B., Morpurgo, A.F., Tarucha, S.: Trilayer graphene is a semimetal with a gate-tunable band overlap. Nat. Nanotechnol. 4, 383-388 (2009)

20. Liu, N., Fu, L., Dai, B., Yan, K., Liu, X., Zhao, R., et al.: Universal segregation growth approach to wafersize graphene from non-noble metals. Nano Lett. 11, 297-303 (2010)

21. Dai, B., Fu, L., Zou, Z., Wang, M., Xu, H., Wang, S., Liu, Z.: Rational design of a binary metal alloy for chemical vapour deposition growth of uniform single-layer graphene. Nat. Commun. 2, 522 (2011)

22. Weatherup, R.S., Bayer, B.C.: In situ characterization of alloy catalysts for low-temperature graphene growth. Nano Lett. 11, $4154-4160$ (2011)

23. Ye, X., Long, J., Lin, Z., Zhang, H., Zhu, H., Zhong, M.: Direct laser fabrication of large-area and patterned graphene at room temperature. Carbon 68, 784-790 (2014)

24. Li, X., Cai, W., Colombo, L., Ruoff, R.S.: Evolution of graphene growth on Ni and Cu by carbon isotope labeling. Nano Lett. 9, 4268-4272 (2009)

25. Vilar, R.: Laser cladding. J. Laser Appl. 11, 64-79 (1999)

26. Gao, W., Zhao, S., Liu, F., Wang, Y., Zhou, C., Lin, X.: Effect of defocus manner on laser cladding of Febased alloy powder. Surf. Coat. Tech. 248, 54-62 (2014)

27. Zang, Z., Nakamura, A., Temmyo, J.: Single cuprous oxide films synthesized by radical oxidation at low temperature for PV application. Opt. Express 21, 11448-11456 (2013)

28. Chen, H., Zhu, W., Zhang, Z.: Contrasting behavior of carbon nucleation in the initial stages of graphene epitaxial growth on stepped metal surfaces. Phys. Rev. Lett. 104, 186101 (2010)

29. Wood, J.D., Schmucker, S.W., Lyons, A.S., Pop, E., Lyding, J.W.: Effects of polycrystalline Cu substrate on graphene growth by chemical vapor deposition. Nano Lett. 11, 4547-4554 (2011)

30. Zhang, Y., Gomez, L., Ishikawa, F.N., Madaria, A., Ryu, K., Wang, C., et al.: Comparison of graphene growth on single-crystalline and polycrystalline Ni by chemical vapor deposition. J. Phys. Chem. Lett. 1, 3101-3107 (2010)

31. Li, Y., Li, M., Gu, T., Bai, F., Yu, Y., Trevor, M., Yu, Y.: An important atomic process in the CVD growth of graphene Sinking and up-floating of carbon atom on copper surface. Appl. Surf. Sci. 284, 207-213 (2013) 